\title{
FACTORS INFLUENCING THE LIFE TABLE STATISTICS OF THE CASSAVA MEALYBUG PHENACOCCUS MANIHOTI
}

\author{
F. SChulthess ${ }^{1}$, J. U. Baumgärtner ${ }^{2}$ and H. R. Herren ${ }^{1}$ \\ 'International Institute of Tropical Agriculture, Oyo Road, PMB 5320, Ibadan Nigeria; \\ ${ }^{2}$ Institute of Phytomedicine, Swiss Federal Institute of Technology, 8092 Zürich, Switzerland
}

(Received 27 November 1986)

\begin{abstract}
Detailed age-specific life table studies were carried out under controlled conditions to measure the effect of temperature, leaf quality $\left(=\right.$ age), variety and plant drought stress on net production rate $\left(R_{0}\right)$, intrinsic rate of increase $\left(r_{m}\right)$ and generation time $(G)$ of Phenacoccus manihoti Mat.-Ferr. in order to explain changes in population densities observed in the field. The developmental threshold calculated from our data and results published by various authors was $14.7^{\circ} \mathrm{C}$. At $35^{\circ} \mathrm{C}$ all mealybugs died before reaching the adult stage. Mealybugs reared on leaves of different ages showed little differences in $r_{m}$, and the higher occurrence of $P$. manihoti on plant tips and oldest leaves could not be explained with better nutritive value of these plant parts alone. Cassava varieties have a strong influence on the intrinsic rate of increase, which could explain differences in results published by other authors. Plant drought stress had little influence on the life table statistics, but rainfall is assumed to be a determinant factor in the dynamics of the mealybug.
\end{abstract}

Key Words: Age-specific life tables, temperature, leaf quality, variety, plant drought stress

\begin{abstract}
Résumé - Des études visant à établir une table de survie détaillée par catégories d'âge ont été menées en environnement contrôlé afin d'évaluer l'impact de la température, de la qualité du feuillage (âge), de la variété et des contraintes hydriques sur le taux de production net $\left(R_{0}\right)$, le taux de croissance intrinsèque $\left(r_{m}\right)$ et la durée des générations $(G)$ de Phenacoccus manihoti Mat.-Ferr. Ces expériences permettent d'expliquer l'évolution de la densité des populations d'insectes telle qu'on peut l'observer en milieu réel. Le seuil de développement calculé à partir de nos données est de $14,7^{\circ} \mathrm{C}$, et correspond aux résultats déjà publiés par plusieurs scientifiques. A $35^{\circ} \mathrm{C}$, toutes les cochenilles meurent avant d'avoir atteint l'âge adulte. Les insectes élevés sur des feuilles d'âges différents ont quasiment le même $r_{m}$. La plus grande incidence de $P$. manihoti à l'extrémité des plants et sur les feuilles plus vieilles n'est pas seulement due à la meilleure valeur nutritive de ces parties végétales. Les variétés de manioc exercent une forte influence sur le taux de croissance intrinsèque, ce qui peut expliquer les divergences apparaissant dans les résultats publiés par d'autres auteurs. Les contraintes hydriques ont peu d'impact sur les données statistiques de la table de survie, bien que la pluviométrie semble constituer un facteur déterminant de la dynamique des populations de cochenilles du manioc.
\end{abstract}

Mots Cléfs: Tables de survie par catégories d'âge, température, qualité du feuillage, variété, contraintes hydriques

\section{INTRODUCTION}

H. R. Herren (this Issue) gives an overview on the importance of the cassava mealybug, Phenacoccus manihoti Mat.-Ferr. (Hom., Pseudococcidae), as a pest in Africa's cassava fields. In addition he presents not only the results of biological control work, but recognizes also the importance of basic ecological studies in the cassava cropping system. For such studies the systems approach provides the necessary theoretical background for the work on the population dynamics of $P$. manihoti and yield formation of its host plant. This paper focuses on the dynamics of $P$. manihoti and presents age-specific life tables for different ecological situations characterized by various factors. These life tables provide an understanding of how various biotic and abiotic factors change pest population densities in the field; an understanding essential for creating optimal rearing conditions for the cassava mealybug and building population models (Gutierrez et al., this Issue).

\section{MATERIALS AND METHODS}

\section{Experimental procedures}

Five factors are recognized to be important for the cassava mealybug life system: temperature, air humidity, leaf quality, variety and drought stress. Air humidity is treated elsewhere (Le Rü and Fabres, 1986) and is therefore omitted in the experimental part of this work. For each of the remaining factors several levels are chosen which represent the experimental conditions for the life table studies. Experiment $\mathrm{A}$ evaluates the temperature influence, $\mathbf{B}$ refers to leaf quality studies, $C$ considers varietal influences, and $D$ explores the influence of drought stress at different temperature levels. 
For each experiment except B, preovipositing females were kept on potted plants at about $28^{\circ} \mathrm{C}$. One week after oviposition started, all egg sacs were removed. Twenty-four hr later, newly laid eggs were collected and transferred to 10 clip cages attached to leaves of potted plants and kept under controlled conditions. Each cage contained 10 to 15 eggs, the development of which was observed daily. Emerged crawlers (40 for each temperature level in A and D, 32 for each level in experiment $C$ ) were transferred to other clip cages and kept individually or in pairs (C). In daily observations time of moulting and survivorship among immature stages were determined. The remaining eggs were further observed for more detailed hatchability studies. In experiment B the eggs were first transferred to Petri dishes that contained two filter papers, a dry one on the bottom and one that was kept constantly humid under the cover. A total of 240 newly moulted crawlers were transferred from this rearing unit to leaf lobes and growing tips in 80 similarly prepared Petri dishes ( 20 per level). To facilitate observations only two folded leaves of about $10 \mathrm{~mm}$ were left on a tip. Thus each Petri dish contained three lobes or three tips with one individual on each. Lobes and tips were replaced every 2 days. After the crawlers had moulted to the second instar, 30 individuals per level were observed as in the above experiment. In all the experiments, ovisacs were removed daily after ovipositing started and eggs were counted under the binocular to determine age-specific fecundity and survivorship.

Thermal conditions. Five levels were used to evaluate the influence of temperature: $20,24,28$, 32 and $35^{\circ} \mathrm{C}$. The relative air humidity could not be controlled satisfactorily and ranged between 65 and $95 \%$. The variety used in this experiment was TMS 30572. The plants were watered three times in 10 days.

Leaf quality. To investigate the development of $P$. manihoti on different plant parts, four different qualities of leaves were considered in this experiment. As a surrogate for leaf quality the position of the leaf in the plant, which determines its age, was used. Thus, the levels of the factor leaf quality consisted of oldest, medium, and youngest leaves and tips, of the variety TMS 30572 . The temperature used in this experiment was $28^{\circ} \mathrm{C}$.

Variety. The monitoring of pest populations every 2 weeks showed higher densities on local varieties than on improved IITA varieties (Hammond et al., this issue). To study the varietal influence on the development of $P$. manihoti, two fast-growing leafy IITA varieties, i.e., TMS 30572 (bitter) and TMS 91934 (bitter), and three local varieties, i.e., the early branching cultivar Ege dudu (bitter), Odongbo (bitter), and Isunikankiyan (sweet), which produce low leaf area indices, were chosen. The constant temperature used during this experiment was $28^{\circ} \mathrm{C}$.

Drought stress and temperature. Outbreaks of $P$. manihoti during the dry season in the absence of natural enemies could be related to two factors, i.e., the absence of the rain as a natural control factor and favourable changes in the physiology of the plant under drought stress that increase the nutritional value of the food (Fabres, 1981; Fabres and Le Rü, 1986). To separate these two factors, potted plants watered only once in 10 days were kept under different constant temperatures $(20,24,28,32$ and $35^{\circ} \mathrm{C}$ ) and compared with plants watered three times in 10 days. In addition, the surface temperature of five leaves was measured with a thermocouple in both treatments and under each constant temperature 30 times during 3 days.

\section{Statistical analysis}

Temperature-dependent development and physiological time. The inverse of the duration in days $(R)$ from egg to egg in experiment $A$ was plotted against the rearing temperature $(T ; \mathrm{Fig} .1)$. In addition data reported in the literature were also considered (Fabres and Boussiengue, 1981; Le Rü and Fabres, 1986). Two different models were used for describing this relationship. Following Campbell et al. (1974), the model

$$
R(T)=a+b \times T
$$

was used for the linear range of the relationship. Consequently the regression line cuts the abscissa at the temperature threshold $\left(T_{0}\right)$ whereas the reciprocal of the slope $(b)$ is the thermal constant $K$, i.e. the number of degree days to complete the prereproductive phase. This model enables the definition of physiological time in units of degree days (Gilbert et al., 1976). For the whole temperature range permitting development (Fig. 1), however, the non-linear polynomial model of Harcourt and Yee (1982) was used.

$$
R(T)=a_{0}+a_{1} \times T+a_{2} \times T^{2}+a_{3} \times T^{3}
$$

According to this non-linear model, physiological time is expressed as a proportion of pre-reproductive development (Stinner et al., 1974).

Life table analysis. Figure 2 shows development of immature stages, age-specific fecundity and survivorship for the non-stress treatment at $28^{\circ} \mathrm{C}$. For this experiment and all remaining life tables, the summary statistics $R_{0}$ (net reproductive rate), $r_{m}$ (intrinsic rate of increase) and $G$ (generation time) were calculated after Birch (1948) with an algorithm provided by A. P. Gutierrez (pers. commun). The statistics as affected by temperatures are presented in Fig. 3. The time is expressed in both days and degree-days. For the discussion, however, only days were used to facilitate comparison with the literature. Additionally, $r_{m}$ is used to compare the factor temperature with corresponding data reported elsewhere (Fig. 4). The influence of the leaf quality and variety factors is shown in Tables 1 and 2 ; a comparison of the same statistics for insects reared on stressed and non-stressed plants is presented in Table 3.

\section{RESULTS}

\section{Threshold estimation and developmental rate}

The relationship between $P$. manihoti development and temperature is shown in Fig. 3. The rate of development was linear between 20 and $27.5^{\circ} \mathrm{C}$ (model A, Gilbert et al., 1976). At $28^{\circ} \mathrm{C}$ the developmental rate $(R)$ began to depart from linearity and declined at $32^{\circ} \mathrm{C}$. No development occurred at $35^{\circ} \mathrm{C}$ where all nymphs died before reaching the preovipositing adult stage. The calculated developmental 


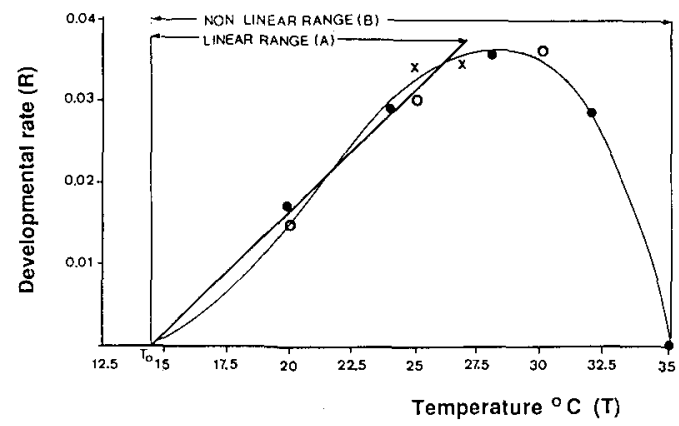

Schulthess

OLe Rü and Fabres (1984)

$\times$ Fabres and Boussiengue (1981)

\section{Linear model $A$}

$R=0.0032 \times T-0.047$ with $r^{2}=0.968$

$T_{0}=14.66$ (temperature threshold)

$K=312.5$ (thermal constant)

Non-linear model $B$

$R=0$ if $(14.6 \geqslant T \geqslant 35.0)$

$R=0.236-0.038 \times T+0.002 \times T^{2}-0.0000304 \times T^{3}$ for range $(14.6<T<35.0)$

Fig. 1. The developmental rate for pre-reproductive life stages of Phenacoccus manihoti as a function of temperature. Two models $(\mathrm{A}, \mathrm{B})$ are used to describe this relationship and are discussed in the text.

threshold in model A, i.e., where $R$ equals zero, was $14.7^{\circ} \mathrm{C}$ and the thermal constant $K$, i.e., the number of degree-days to complete the pre-reproductive phase, was 312.5 . Hence, the non-linear polynomial model (model B) after Harcourt and Yee (1982) was used to predict the development of $P$. manihoti between the calculated lower developmental threshold $\left(T_{0}\right)$ and $35^{\circ} \mathrm{C}$. The observed data points fitted the prediction curve satisfactorily. The equations for both functions are presented in Fig. 2.

Net reproduction rate. Several authors observed highest $R_{0}$ between 20 and $24^{\circ} \mathrm{C}$ (Lema and Herren, 1985; Fabres and Le Rü, 1986; Nsiame She, 1986). In our experiment, $R_{0}$ was highest at $28^{\circ} \mathrm{C}$ and decreased rapidly afterwards to zero at $35^{\circ} \mathrm{C}$ (Fig. 3). At this extreme temperature all nymphs died before reaching the preovipositing stage and no life table statistics could be calculated. The highest reproduction rate was in the range of those reported by Le Rü and Fabres (1986) but was substantially lower than those calculated by Lema and Herren (1985) and Nsiame She (1986), who used a sweet variety (TMS 3001) in their experiments.

Generation time. The mean generation time $(G)$ in days decreased from 81 days at $20^{\circ} \mathrm{C}$ to 35 days at $32^{\circ} \mathrm{C}$. At $20^{\circ} \mathrm{C} G$ was considerably higher than re-

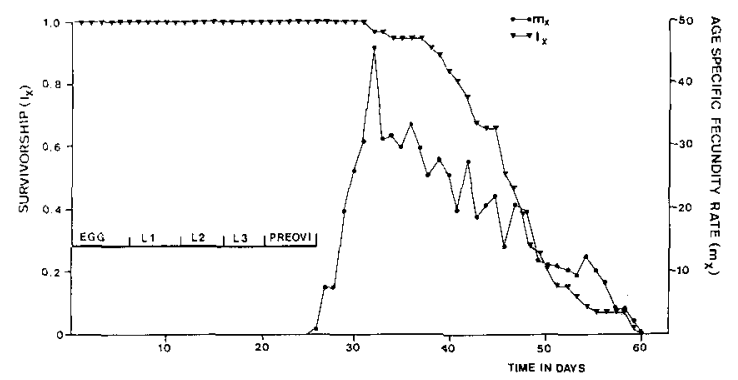

Fig. 2. Development time of immature stages $(\mathrm{EGG}=$ eggs; L1, L2, L3 = larvae and nymphs; PREOVI = prereproductive adult stage), age-specific fecundity rate $\left(m_{x}\right)$ and survivorship $\left(l_{x}\right)$ of Phenacoccus manihoti at $28^{\circ} \mathrm{C}$. ported by other authors (Le Rü and Fabres, 1986; Lema and Herren, 1985; Nsiame She, 1986) but was similar in the medium and upper temperature range.

Intrinsic rate of increase. Figure 4 shows a comparison of $r_{m}$ values published by different authors. In our experiments $r_{m}$ calculated on a day basis reached a maximum of 0.18 at $28^{\circ} \mathrm{C}$ and decreased afterwards to 0.12 at $32^{\circ} \mathrm{C}$. Lema and Herren (1985) and Nsiame She (1986) reported optimum $r_{m}$ values that remained on a similar level between 28 and $32.5^{\circ} \mathrm{C}$. In the experiments of Le Rü and Fabres (1986) the highest $r_{m}, 0.214$, was reached at $30^{\circ} \mathrm{C}$. It should be noted that Le Rü and Fabres (1986) used an approximation of $r_{m}\left(r_{c}\right)$ which proved to be strongly correlated with the $r_{m}$ (Le Rü and Papierok, 1986). In our and Lema and Herren's (1985) experiments, no oviposition was observed at 35 and $34^{\circ} \mathrm{C}$, respectively, whereas Nsiame She (1986) obtained a still considerably high $r_{m}$ of 0.104 at $34^{\circ} \mathrm{C}$.

\section{Influence of leaf quality on the life table statistics}

Studies on the within-plant distribution of $P$. manihoti showed a higher aggregation on the oldest leaves and the growing tips. A similar distribution was observed for aphids and attributed to the higher nutritive value of these plant parts (Kennedy, 1958). The life table studies on $P$. manihoti reared on leaves of different ages and tips, however, resulted in a highest $r_{m}$ for oldest leaves, but lowest for tips (Table 1). Generally, the differences between the $r_{m}$ values were small and $r_{m}$ ranged from 0.1715 to 0.1774 . The net reproduction rates were between 230.9 on the oldest leaves and 329 on the medium leaves; the low $R_{0}$ on the oldest leaves was compensated for by the shortest generation time observed in these experiments. As opposed to the above experiments, mealybugs in these studies were reared on detached leaf lobes. But this procedure did not appear to affect $r_{m}$ to a great extent.

\section{Varietal influence}

Table 2 presents the life table statistics of $P$. manihoti reared on different varieties. Generally, the 

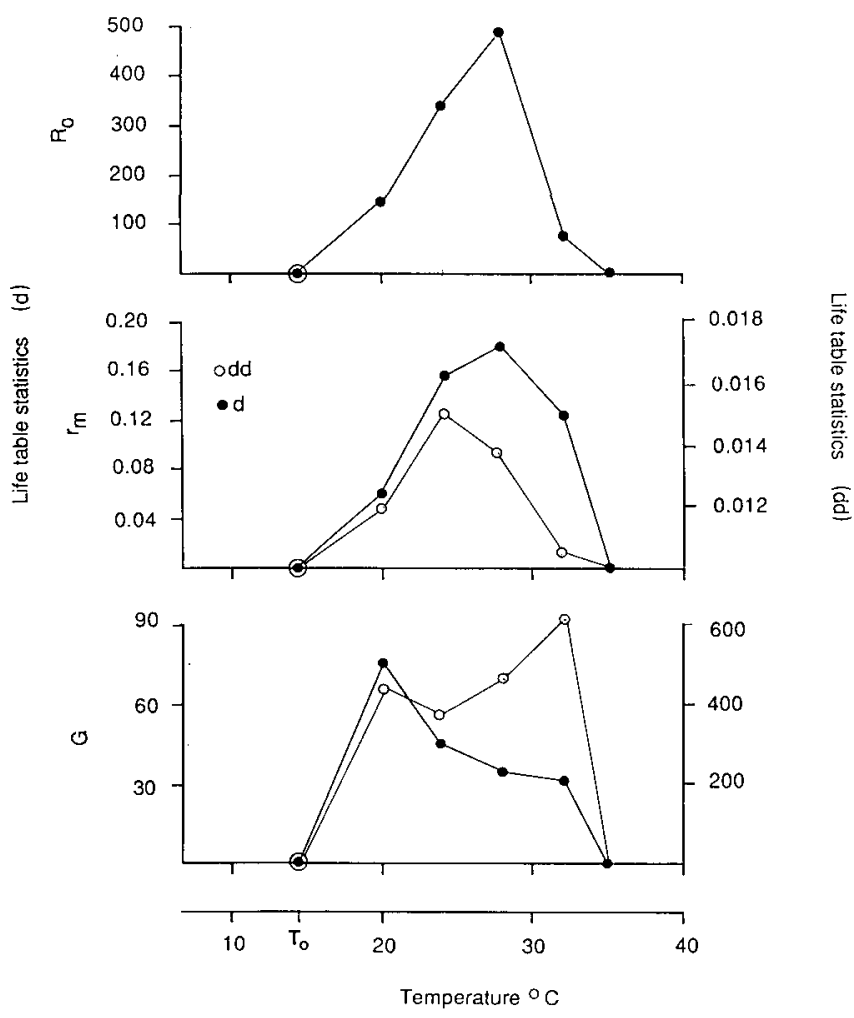

Fig. 3. Net reproduction rate $\left(R_{0}\right)$, intrinsic rate of increase $\left(r_{m}\right)$ and generation time $(G)$ for Phenacoccus manihoti as a function of temperature with time expressed in days $(d)$ and degree-days $(d d)$.

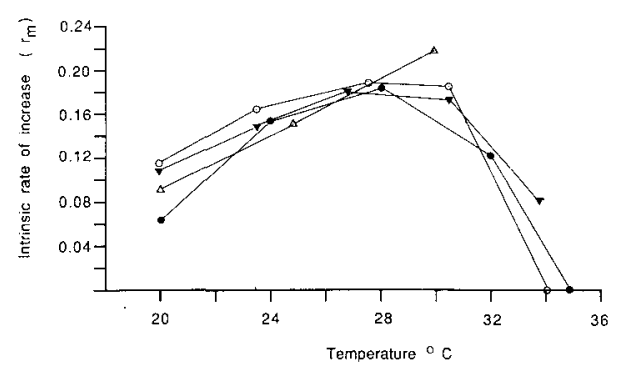

$\nabla$ Nsiame She (1986)

$\triangle$ Le Rü and Fabres (1984)

OLema and Herren (1982)

OSchulthess

Fig. 4. Intrinsic rate of increase $\left(r_{m}\right)$ as a function of temperature for $P$. manihoti published by different authors.
Table 1. Influence of leaf quality on the life table statistics of Phenacoccus manihoti

\begin{tabular}{lccc}
\hline Leaf quality & $r_{m}$ & $R_{0}$ & $G$ \\
\hline Old leaf & 0.1774 & 230.93 & 31.87 \\
Medium leaf & $\mathbf{0 . 1 7 2 4}$ & 329.23 & 35.03 \\
Youngest leaf & 0.1740 & 323.75 & 34.92 \\
Growing tip & 0.1715 & 273.73 & 34.22 \\
\hline
\end{tabular}

variety had a greater influence than the leaf quality. The $r_{m}$ ranged from 0.157 on TMS 91934 to 0.174 on the local variety Ege dudu, which also had the second highest net reproductive rate and the shortest generation time. The widely distributed local variety Odongbo, however, had the second lowest $r_{m}$ observed in these experiments. Mealybugs reared on the sweet variety Isunikankiyan had the highest $R_{0}$ but also the longest generation time.

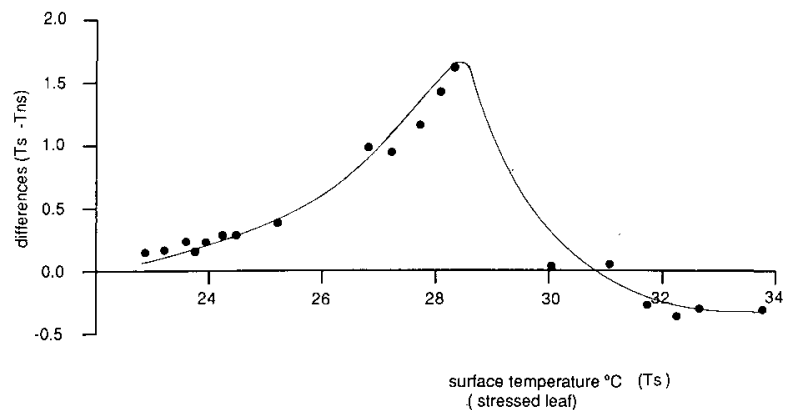

Fig. 5. Differences in leaf temperature on stressed (Ts) and non-stressed (Tns) plants as a function of Ts in consecutive measurements. 
Table 2. Influence of the cassava variety on the life table statistics of Phenacoccus manihoti

\begin{tabular}{lccc}
\hline Variety & $r_{m}$ & $R_{0}$ & $G$ \\
\hline 91934 (bitter, improved, resistant) & 0.1573 & 357.44 & 39.80 \\
ODONGBO (bitter, local, susceptible) & 0.1612 & 356.19 & 38.27 \\
ISUNIKANK YIAN (sweet, local, susceptible) & 0.1636 & 467.91 & 40.21 \\
30572 (bitter, improved, susceptible) & 0.1641 & 358.19 & 37.79 \\
EGE DUDU (bitter, local, susceptible) & 0.1704 & 414.68 & 37.67 \\
\hline
\end{tabular}

\section{Influence of drought stress}

Table 3 shows the life table statistics from the stress and non-stress experiments at different constant temperatures. Generally, the calculated $r_{m}$ and $R_{0}$ values tended to be higher on stressed plants, the differences, however, were very small in comparison to those found by Fabres and Le Rü (1986) in a similar experiment. The biggest differences in $R_{0}$ and $G$ were found at the lowest and the highest temperature levels; at $35^{\circ} \mathrm{C}$ eggs were laid only on stressed plants. The measurement of leaf temperature showed increasing differences between stressed and nonstressed plants as $T_{s}$ increased. Daily mean difference reached a maximum of $1.6^{\circ} \mathrm{C}$ at a $T_{s}$ of $28.5^{\circ} \mathrm{C}$ and then decreased. At the higher $T_{s}$ range $\left(30-34^{\circ} \mathrm{C}\right)$ the temperature on stressed leaves was lower than on non-stressed.

\section{DISCUSSION}

The temperature threshold at $14.7^{\circ} \mathrm{C}$, calculated from the linear relationship in Fig. 2, was $10^{\circ}$ higher than the value found by Nsiame She (1986). However, Nsiame She used the entire temperature range from 20 to $34^{\circ} \mathrm{C}$ to describe the $R-T$ relationship, which started to deviate from linearity at $27^{\circ} \mathrm{C}$. The $T_{0}$ of $14.7^{\circ} \mathrm{C}$ is also in the range of the value found for the host plant $\left(13.0^{\circ} \mathrm{C}\right.$; Keating and Evenson, 1979), the cassava green mite Mononychellus tanajoa (Bondar) sensu lato $\left(14.4^{\circ} \mathrm{C}\right.$; Yaninek, this Issue), and the parasitic wasp Epidinocarsis lopezi (De Santis) $\left(15.4^{\circ} \mathrm{C}\right.$; Löhr, pers. commun.) and will be used in further studies on the dynamics of $P$. manihoti.

There are differences in $G$ and $R_{0}$ according to leaf quality, but $r_{m}$ does not differ greatly. As expected, other factors not considered here are more important for explaining the within-plant distribution. Field observations confirm the results of the study by Fabres and Le Rü (1986) who found that the movement of mealybugs within the plant and between the ground and the plant must also be taken into account. In addition mortality factors like natural enemies and wind could act differently on different strata of the plant and thereby change the distribution.
As shown in Table 2, the cassava variety influenced the development of $P$. manihoti population growth to a greater extent than did age (= quality) of plant parts. This could explain the different life table statistics published by other authors (Fig. 3). Thus, Lema and Herren (1985) and Nsiame She (1986) reported considerably higher $R_{0}$ and lower $G$ values for $P$. manihoti reared on the sweet variety TMS 3001. Yaninek (this issue) also found the highest fecundity for $M$. tanajoa reared on the sweet variety Isunikankiyan. This could indicate an antibiotic effect of the cyanide content in the "bitter" cassava leaves. However, further research is needed to confirm this conclusion. On the other hand, the relatively low $r_{m}$ value found on the popular local variety Odongbo is in opposition to the development of considerably higher mealybug densities in the field on this cultivar as observed by Schulthess (unpublished data) and Hammond et al. (this issue). Thus, further studies on host-plant-pest and hostplant-natural enemies interaction are needed to explain these differences in $P$. manihoti population densities.

Plant drought stress mainly influenced the net reproduction rates and had little effect on $r_{m}$ and $G$ in the medium temperature range where the differences in the life table statistics can mainly be explained with differences in leaf temperature. At 20 and $35^{\circ} \mathrm{C}$, however, the leaf temperatures in both treatments were nearly the same and the differences in $r_{m}$ were high, which may point to a change of the nutritive value of the phloem sap if stress is applied under these extreme temperatures. In general, daily average temperatures in Nigeria's cassava growing areas are rarely outside the range of $24-30^{\circ} \mathrm{C}$. For this temperature range differences in the life table statistics due to drought stress are rather small and, hence, are unlikely to explain mealybug outbreaks in the dry season. Additional factors not discussed in this work appear more important for reducing densities during the rainy season. Among them is the mechanical effect of the rain (Fabres, 1981) and the incidence of entomophagous fungi (Le Rü, 1986), while air humidity has little influence (Le Rü and Fabres, 1986).

Table 3. Comparison of the life table statistics of Phenacoccus manihoti reared on stressed and non-stressed plants

\begin{tabular}{|c|c|c|c|c|c|c|c|c|c|c|}
\hline \multirow[b]{3}{*}{ Statistics } & \multicolumn{10}{|c|}{ Treatment } \\
\hline & \multicolumn{2}{|c|}{$20^{\circ} \mathrm{C}$} & \multicolumn{2}{|c|}{$24^{\circ} \mathrm{C}$} & \multicolumn{2}{|c|}{$28^{\circ} \mathrm{C}$} & \multicolumn{2}{|c|}{$32^{\circ} \mathrm{C}$} & \multicolumn{2}{|c|}{$35^{\circ} \mathrm{C}$} \\
\hline & ns & $\mathbf{s}$ & ns & $\mathbf{s}$ & ns & $\mathbf{s}$ & ns & $\mathbf{s}$ & ns & $\mathbf{s}$ \\
\hline$R_{0}$ & 147.2 & 200.5 & 344.0 & 388.4 & 485.7 & 546.6 & 70.0 & 88.9 & no & 6.7 \\
\hline$r_{m}$ & 0.062 & 0.075 & 0.151 & 0.157 & 0.183 & 0.187 & 0.123 & 0.127 & no & 0.052 \\
\hline$\vec{G}$ & 82.2 & 73.3 & 40.8 & 40.1 & 36.5 & 34.3 & 35.4 & 36.3 & no & 37.4 \\
\hline
\end{tabular}

no $=$ no oviposition. 


\section{REFERENCES}

Birch L. C. (1948) The intrinsic rate of natural increase of an insect population. J. Anim. Ecol. 17, 15-26.

Campbell A., Frazer B. D., Gilbert N., Gutierrez A. P. and Mackauer M. (1974) Temperature requirements of some aphids and their parasites. J. Appl. Ecol. 11, 431-438.

Fabres G. (1981) Dynamics of cassava mealybug populations in the People's Republic of Congo. Proc. of the first Triennial Root Crop Symp. of the Int. Soc. for Tropical Root Crops Africa Branch, 8-12 September 1980, Ibadan, Nigeria.

Fabres G. and Boussiengue J. (1981) Bioécologie de la cochenille du manioc Phenacoccus manihoti (Hom. Pseudococcidae) en Republique Populaire du Congo. Extrait de l'Agronomie Tropicale $X X X V I-1$ Janvier-mars 1981, pp. 6-13.

Fabres G. and Le Rü B. (1986) Ettude des relations plantinsecte pour la mise au point de méthodes de régulation des populations de la cochenille du manioc. In " $L a$ cochenille $d u$ manioc et sa biocoenose au Congo, 1979-1984", Travaux de l'équipe Franco-Congolaise ORSTOM-DGRS, Brazzaville, BP 181, RP du Congo.

Gilbert N., Gutierrez A. P., Frazer B. D. and Jones R. E. (1976) Ecological Relationships. Freeman, Reading and San Francisco.

Harcourt D. G. and Yee J. M. (1982) Polynomial algorithm for predicting the duration of insect life stages. Environ. Ent. 11, 581-584.

Keating B. A. and Evenson J. P. (1979) Effect of soil temperature on sprouting and sprout elongation of stem cuttings of cassava (Manihot esculenta Crantz) Field Crops Res. 5, 271-281.

Kennedy J. S. (1958) Physiological condition of the hostplant and susceptibility to aphid attack. Ent. Exp. Appl. $1,11-65$.
Lema K. M. and Herren H. R. (1985) Influence of constant temperature on population growth rates of the cassava mealybug Phenacoccus manihoti. Ent. exp. appl. 38, 165-169.

Le Rü B. and Fabres G. (1986) Influence de la temperature et de l'hygrométrie relative sur le taux d'accroissement des populations de la cochenille du manioc, Phenacoccus manihoti (Hom. Pseudococcidae) au Congo. In " $\mathrm{La}$ cochenille du manioc et sa biocoenose au Congo 1979-1984". Travaux de l'équipe Franco-Congolaise ORSTOM$D G R S$, Brazzaville, BP 181, RP du Congo, p. 39-55.

Le Rü B. and Papierok B. (1986) Taux intrinsèque d'accroissement naturel de la cochenille du manioc, Phenacoccus manihoti Matile-Ferrero (Homoptères, Pseudococcidae). Interêt d'une methode simplifiée d'estimation de $r_{m}$. In "La cochenille du manioc et sa biocoenose au Congo 1979-1984". Travaux de l'équipe Franco-Congolaise ORSTOM-DGRS, Brazzaville BP 181, RP du Congo, pp. 14-26.

Le Rü B. (1986) Étude de l'évolution d'une mycose à Neozygites fumosa (Zygomycetes, Entomophthorales) dans une population de la cochenille du manioc Phenacoccus manihoti (Hom.: Pseudococcidae). In "La cochenille du manioc et sa biocoenose au Congo, 1979-1984", Travaux de l'équipe Franco-Congolaise ORSTOM-DGRS, Brazzaville, BP 181, RP du Congo.

Nsiame She H. D. (1986) The bioecology of the predator, Hyperaspis jucunda Muls (Coleoptera, Coccinellidae) and the temperature response of its prey, the cassava mealybug, Phenacoccus manihoti Mat.-Fer. (Homoptera, Pseudococcidae). Thesis in the Department of Agricultural Biology, University of Ibadan, Ibadan, Nigeria.

Stinner R. E., Gutierrez A. P. and Butler G. D. (1974) An algorithm for temperature growth rate simulation. Can. Ent. 106, 519-524. 